\title{
CORRECTION
}

\section{Correction to: A Stanley-Elder theorem on Cranks and Frobenius symbols}

George E. Andrews ${ }^{*}$, Manosij G. Dastidar ${ }^{2}$ and Thomas Morrill ${ }^{3}$

${ }^{\text {*Correspondence: }}$

gea1@psu.edu.in

${ }^{1}$ Pennsylvania State University,

University Park, PA 16802, USA

Full list of author information is

available at the end of the article
Correction to: G.E. Andrews et al. Res. Number Theory (2021) 7:56. https://doi.org/10.1007/s40993-021-00285-7

In the original article the affiliations were incorrectly assigned; they are correct here. Author details

${ }^{1}$ Pennsylvania State University, University Park, PA 16802, USA, ${ }^{2}$ Technische Universität Wien, 1040 Vienna, Austria,

${ }^{3}$ Trine University, One University Avenue, Angola, IN 46703, USA.

The original article can be found online at https://doi.org/10.1007/s40993-021-00285-7.

Published online: 3 November 2021

Publisher's Note

Springer Nature remains neutral with regard to jurisdictional claims in published maps and institutional affiliations. 